\title{
LEY APLICABLE AL RÉGIMEN ECONÓMICO MATRIMONIAL DESPUÉS DE LA DISOLUCIÓN DEL MATRIMONIO TRAS LA ENTRADA EN VIGOR DEL REGLAMENTO UE 2016/1104'
}

\author{
María José Cazorla González \\ Profesora Titular de Derecho civil \\ Universidad de Almería-SEJ235 (CIDES-CEIA3) \\ E-mail: mcazorla@ual.es
}

\begin{abstract}
RESUMEN: Se analiza la competencia del órgano jurisdiccional para disolver el divorcio y la ley aplicable al régimen económico matrimonial de un matrimonio transfronterizo cuya demanda se presenta cuando el Reglamento 2016/1103 ya está en vigor, y los cónyuges pueden a través del principio de libre elección determinar o cambiar de común acuerdo la ley aplicable a su régimen económico matrimonial entre la que se encuentra la residencia habitual; ya que aparecen dos perspectivas diferentes entre la aplicación del derecho civil nacional y el derecho a la movilidad transfronteriza en el territorio comunitario para todo ciudadano europeo. Así las disposiciones del Reglamento 1103 no restringen la aplicación de las leyes de policía de la ley del foro (nacional) y la cuestión de orden público como causa para rehusar la aplicación de la ley nacional de un Estado, queda matizada tal y como se recogen en sentencias del TJUE y en la aplicación del Reglamento desde diferentes escenarios a través de un caso hipotético, que pretende clarificar la aplicación del Reglamento (UE) 2016/1103.
\end{abstract}

Palabras clave: competencia; ley aplicable; regímenes económicos matrimoniales; matrimonios transfronterizos

\begin{abstract}
It analyses the jurisdiction of the court to dissolve the divorce and the law applicable to the matrimonial property regime of a cross-border marriage for which the application is made when Regulation 2016/1103 is already in force, and the spouses can, by means of the principle of free choice, determine or change by common agreement the law applicable to their matrimonial property regime, including the law of habitual residence; since two different perspectives appear between the application of national civil law and the right to cross-border mobility on Community territory for every European citizen. Thus the provisions of Regulation 1103 do not restrict the application of the mandatory rules of the law of the forum (national)
\end{abstract}

1 Trabajo desarrollado en el proyecto PERSONALIZED SOLUTION IN EUROPEAN FAMILY AND SUCCESSION LAW (PSEFS) concedido por el programa de la Unión Europea JUSTICE en la convocatoria: JUST-JCOO-AG-2017. 
and the question of public policy as a reason for refusing the application of the national law of a State is qualified as set out in judgments of the CJEU and in the application of the Regulation from different scenarios through a hypothetical case, which seeks to clarify the application of Regulation (EU) 2016/1103.

Keywords: jurisdiction; applicable law; matrimonial property regimes; crossborder marriages

SUMARIO: I. CUESTIONES GENERALES COMUNES A LOS ESTADOS MIEMBROS DE LA UE PARA LA APLICACIÓN DE LA LEY DEL FORO: RESPETO A LA LIBERTAD Y EL DERECHO A LA MOVILIDAD TRANSFRONTERIZA. II. LEY aplicable bajo los reglamentos comunitarios. 2.1. Antecedentes. 2.2. Aplicación de la Ley según lo dispuesto en los Reglamentos 1103 y 1104 de la UE. III. DESCRIPCIÓN DE UN CASO HIPOTÉtICO. 3.1 Variables que afectan a los divorcios tras la entrada en vigor del Reglamento UE 2016/1103. 3.2. Análisis de posibles escenarios. IV. Conclusiones. V. Bibliografía.

\section{CUESTIONES GENERALES COMUNES A LOS ESTADOS MIEMBROS DE LA UE PARA LA APLICACIÓN DE LA LEY DEL FORO: RESPETO A LA LIBERTAD Y EL DERECHO A LA MOVILIDAD TRANSFRONTERIZA}

Nuestra Europa diversa presenta diferentes situaciones de hecho atendiendo a la ley de foro nacional. En este sentido y respecto de la materia que nos ocupa ahora, debemos saber que seis países miembros de la UE no contempla regulación alguna sobre las uniones registradas: Bulgaria, Letonia, Lituania, Polonia, Rumanía y Eslovaquia. Donde además no se permite el matrimonio entre personas del mismo sexo ni ningún otro tipo de unión civil. Situación que no parece que vaya a cambiar en estos países a corto o medio plazo.

Los recientes Reglamentos comunitarios 1103/2016 y 1104/2016 que entraron en vigor el 29 de mayo de $2019^{2}$, comparten estructura, objetivos y la práctica totalidad de su literalidad, si bien el primero regula los regímenes económico matrimoniales, mientras que el segundo recoge los efectos patrimoniales de las uniones registradas, siguiendo el princi-

2 Reglamento (UE) 2016/1103 del Consejo, de 24 de junio de 2016, por el que se establece una cooperación reforzada en el ámbito de la competencia, la ley aplicable, el reconocimiento y la ejecución de resoluciones en materia de regímenes económicos matrimoniales. Y el Reglamento (UE) 2016/1104 del Consejo de 24 de junio de 2016 por el que se establece una cooperación reforzada en el ámbito de la competencia, la ley aplicable, el reconocimiento y la ejecución de resoluciones en materia de efectos patrimoniales de las uniones registradas.

Ambas normativas, en sus respectivos artículos 70 establecieron que su entrada en vigor sería a los veinte días de su publicación en el Diario Oficial de la Unión Europea, siendo aplicable en los Estados miembros que participen en una cooperación reforzada en el ámbito de la competencia, la ley aplicable, el reconocimiento y la ejecución de resoluciones relativas a los regímenes económicos de las parejas internacionales, tanto en materia de regímenes económicos matrimoniales como de efectos patrimoniales de las uniones registradas, autorizada por la Decisión (UE) 2016/954

El presente Reglamento es de aplicación desde el 29 de enero de 2019, con excepción de sus artículos 63 y 64, que vienen siendo aplicables un año antes, concretamente desde el 29 de abril de 2018, y de sus artículos 65, 66 y 67, que son aplicables desde el 29 de julio de 2016, para todos los Estados miembros que participen en una cooperación reforzada en virtud de una decisión adoptada de conformidad con el artículo 331.1 del TFUE. 
pio de igualdad en el ejercicio de los derechos que le corresponde tanto al consorte como a la pareja de hecho registrada, y ya manifestada por nuestro TJUE en la sentencia de 25 de julio de 2008, Metock y otros, C-127/08, EU:C:2008:449, apartados 98 y 99), donde se equipara el cónyuge a la pareja de hecho cuando el consorte bajo la definición que el art.2.2 en la Directiva 2004/38 da al cónyuge como miembro de la familia en un plano de igualdad y de no discriminación; si bien no por aplicación analógica ya que son dos instituciones (matrimonio y pareja de hecho registradas) diferentes que se constituyen por libertad de las partes atendiendo a los aspectos formales que conforman el negocio jurídico.

Esta doctrina del TJUE fue la que mayoritariamente ha venido siendo establecida por el Tribunal Supremo en España (STS 21 octubre de 1992) , $^{3}$ que sin dejar de aplicar el principio de igualdad como cónyuges o como parejas more uxorio bajo el articulo 32 y 39 de la Constitución española, no los ha equiparado bajo la analogía la aplicación del mismo régimen jurídico a los efectos tras la ruptura.

En esta sentencia, se determina que no existe identidad entre matrimonio y parejas de hecho, pues sería injustificable no respetar en un negocio jurídico voluntario el pleno respeto por la presunta voluntad de los convivientes, tanto como matrimonio como en pareja de hecho; ya que España admite y regula ambas opciones. De tal forma, que los se unieron pudiendo haberse casado, lo hicieron precisamente para quedar excluidos de la disciplina matrimonial y no sometidos a la misma, por lo que actuar en contra de tal decisión no se ajustaría a los valores y principios establecidos en nuestro ordenamiento jurídico. Es decir, que no cabe la aplicación analógica a las uniones extramatrimoniales de la normativa matrimonial, porque ello constituiría una flagrante violación del principio de libertad individual y equivaldría a imponerles unos efectos jurídicos que, en su momento, los convivientes no quisieron.

Por otra parte, y siguiendo la STS de 30 de diciembre de $1994^{4}$ tampoco podemos decir que encontremos una laguna legal que amparara el recurso analógico, pues los países que no la regulan no implica que no se de la casuística, sino simplemente que no tienen un registro donde conste la unión; lo que tampoco quiere decir que exista un vacío que deba ser llevado por el marco jurídico que regula el matrimonio, pues ello supondría establecer a una situación de facto una aplicación reglamentaria contraria al ejercicio de su libertad.

Finalmente, esto se constata con los recientes Reglamentos comunitarios desde la legislación europea se reconoce a cada institución su lugar pero sin identificarlas de manera análoga.

Si a esto añadimos, que el artículo el artículo 22 de cada uno de los Reglamentos reconoce bajo el principio de libre elección de la ley aplicable que los interesados pueden determinar o cambiar de común acuerdo la ley aplicable a su régimen económico matrimonial o a los efectos patrimoniales de su unión registrada, siempre que nos encontremos ante alguna de las siguientes leyes, entre la que se encuentra la residencia habitual ${ }^{5}$, apa-

3 Criterio mayoritario de nuestra jurisprudencia desde 1992 con la STS de 21 de octubre de 1992.

ALVAREZ LATA, N.: "Las parejas de hecho: perspectiva jurisprudencial”. Dialnet. 1998.

5 Con relación al matrimonio, la ley del Estado en el que los cónyuges o futuros cónyuges, o uno de ellos, tengan su residencia habitual en el momento de la celebración del acuerdo, o la ley del Estado de la nacionalidad de cualquiera de los cónyuges o futuros cónyuges en el momento en que se celebre el acuerdo: 
rece dos perspectivas diferentes entre la aplicación del derecho civil nacional y el derecho a la movilidad transfronteriza en el territorio comunitario para todo ciudadano europeo y los miembros de su familia, como pudiera ser el cónyuge o pareja de hecho registrada conforme a la legislación vigente de cualquiera de los estados miembros, a partir de la que poder comenzar a ejercitar su derecho de residencia ${ }^{6}$.

Pareciera que las disposiciones del Reglamento 1103 Y 1104, cuando en sus respectivos artículos 30, afirman que no restringirán la aplicación de las leyes de policía de la ley del foro (nacional) cuya observancia era considerada esencial, hasta el punto de ser aplicables a toda situación que se produzca dentro de su ámbito de aplicación, independientemente de régimen jurídico económico matrimonial aplicable en virtud del presente Reglamento. Para añadir a continuación en el art. 31 la cuestión de orden público como causa para rehusar la aplicación de la ley nacional de un Estado cuando la aplicación de la disposición sea manifiestamente incompatible con el orden público del foro.

La sociedad europea viene cambiando en las últimas décadas, y esto se refleja en las diferentes formas de familia que actualmente conviven en nuestro territorio europeo, y cuya realidad, bajo el principio de igualdad y de no discriminación, ha venido manteniendo el Tribunal Europeo de Derechos Humanos cuando determinada en sus sentencias ${ }^{7}$ que una pareja homosexual puede estar comprendida en el concepto de "vida privada" y en el de "vida familiar" del mismo modo que la de una pareja heterosexual que se encuentre en la misma situación.

Pero es solo apariencia, pues la gran sala de nuestro TJUE en sentencia de 5 de junio de 2018, que afectaba al matrimonio de dos personas del mismo sexo, una de ellas ciudadano rumano y cuyo artículo 277 del Código Civil rumano prohíbe el matrimonio entre personas del mismo sexo, negándoles todo reconocimiento legal a aquellos contraídos fuera de su Estado, si bien finaliza en su párrafo $4^{\circ}$ regulando que serán de aplicación las disposiciones legales relativas a la libre circulación en el territorio rumano de los ciudadanos de los Estados miembros de la Unión Europea y del Espacio Económico Europeo.

Nuestro Tribunal de Justicia ha venido dando cuenta de ello, bajo la aplicación de la Directiva 2004/38, cuyo artículo 2, titulado «Definiciones», establece lo siguiente en su punto 2 , letras a) cónyuge y b) pareja ${ }^{8}$.

En relación a la unión registrada, la ley del Estado en el que los miembros o futuros miembros de la unión registrada, o uno de ellos, tengan su residencia habitual en el momento de la celebración del acuerdo, la ley del Estado de la nacionalidad de cualquiera de los miembros o futuros miembros de la unión registrada en el momento en que se celebre el acuerdo, o la ley del Estado conforme a cuya ley se haya creado la unión registrada. Todo ello siempre que la ley elegida, sea cual fuere, atribuya efectos patrimoniales a la institución de la unión registrada.

6 En este sentido vid. JIMÉNEZ BLANCO, P.: "La movilidad transfronteriza de matrimonios entre personas del mismo sexo: la UE da un paso. Sentencia del Tribunal de Justicia de 5 de junio de 2018, asunto C-673/18: Coman”. La Ley Unión Europea, N. ${ }^{\circ} 61,31$ de Julio de 2018.

7 TEDH, sentencia de 7 de noviembre de 2013, Vallianatos y otros c. Grecia, CE:ECHR:2013:1107JUD002938109 y TEDH, sentencia de 14 de diciembre de 2017, Orlandi y otros c. Italia, CE:ECHR:2017:1214JUD002643112.

8 «A los efectos de la presente Directiva, se entenderá por:

2) "Miembro de la familia":

a) el cónyuge; El concepto de «cónyuge» al que se refiere dicha disposición designa a una persona unida a otra por vínculo de matrimonio (véase, en este sentido, la sentencia de 25 de julio de 2008, Metock y otros, C-127/08, EU:C:2008:449, apartados 98 y 99) lo equipara a la pareja de hecho.

b) la pareja con la que el ciudadano de la Unión ha celebrado una unión registrada, con arreglo a la legislación de un Estado miembro, si la legislación del Estado miembro de acogida otorga a las uniones registradas un trato 
Y mas recientemente, la Gran sala del TJUE, en sentencia de 5 de junio de 2018 ha venido a recordar que un Estado miembro no puede invocar su Derecho nacional para oponerse al reconocimiento en su territorio, al objeto únicamente de conceder un derecho de residencia derivado a un nacional de un tercer Estado, del matrimonio contraído por este con un ciudadano de la Unión del mismo sexo en otro Estado miembro de conformidad con el Derecho de este último.

Por su parte, el Gobierno letón ha señalado en la vista que, suponiendo que la negativa, en circunstancias como las que son objeto del litigio principal, a reconocer los matrimonios entre personas del mismo sexo contraídos en otro Estado miembro constituya una restricción al artículo 21 TFUE, tal restricción está justificada por razones relacionadas con el orden público y la identidad nacional, a la que se refiere el artículo 4 TFUE, apartado 2.

Este tribunal ha venido reiterando tanto, el orden público solo puede invocarse en caso de que exista una amenaza real y suficientemente grave que afecte a un interés fundamental de la sociedad (véanse, en este sentido, las sentencias de 2 de junio de 2016, Bogendorff von Wolffersdorff, C-438/14, EU:C:2016:401, apartado 67, y de 13 de julio de 2017, E, C-193/16, EU:C:2017:542, apartado 18 y jurisprudencia citada).

A este respecto, debe hacerse constar que la obligación de un Estado miembro de reconocer un matrimonio entre personas del mismo sexo contraído en otro Estado miembro de conformidad con el Derecho de ese Estado, al objeto únicamente de conceder un derecho de residencia derivado a un nacional de un tercer Estado, no afecta negativamente a la institución del matrimonio en el primer Estado miembro, que se define por el Derecho nacional y que entra dentro de la competencia de los Estados miembros, como se ha recordado en el apartado 37 de la presente sentencia. No supone que dicho Estado miembro contemple, en su Derecho nacional, la institución del matrimonio entre personas del mismo sexo. Se limita a la obligación de reconocer tales matrimonios, contraídos en otro Estado miembro de conformidad con el Derecho de este, y ello a los solos efectos del ejercicio de los derechos que para esas personas se derivan del Derecho de la Unión.

Así, tal obligación de reconocimiento al objeto únicamente de conceder un derecho de residencia derivado a un nacional de un tercer Estado no atenta contra la identidad nacional ni amenaza el orden público del Estado miembro afectado.

\section{LEY APLICABLE BAJO LOS REGLAMENTOS COMUNITARIOS}

\subsection{Antecedentes}

Hasta el 26 de enero de 2019, acudíamos al artículo 9.2 del Código civil en España para aplicar la norma de conflicto en caso de divorcio, precepto que es equivalente a existentes en las legislaciones de los Estados Miembros.

equivalente a los matrimonios y de conformidad con las condiciones establecidas en la legislación aplicable del Estado miembro de acogida;

$[\ldots] »$. 
De ahí que cuando había que determinar la competencia judicial y el orden jurisdiccional aplicable, nos viéramos obligados a acudir al Reglamento de Roma III, que distingue dos posibilidades atendiendo a la libre voluntad o cuando se carece de ella al no haber los cónyuges o pareja de hecho registrada elegido ley aplicable.

En el primer caso permite a los cónyuges una autonomía de la voluntad conflictual limitada, ya que pueden elegir uno de los ordenamientos jurídicos previstos en el artículo 5 del Reglamento Roma III:

- la ley del Estado en que los cónyuges tengan su residencia habitual en el momento de la celebración del convenio;

- o la ley del Estado del último lugar de residencia habitual de los cónyuges, siempre que uno de ellos aún resida allí en el momento en que se celebre el convenio;

- o la ley del Estado cuya nacionalidad tenga uno de los cónyuges en el momento en que se celebre el convenio,

- o la ley del foro.

Sin embargo, en aquellos supuestos en que los cónyuges no hubieran elegido la ley aplicable o el acuerdo no fuera válido, resultarán de aplicación las conexiones objetivas, reguladas en el artículo 8 del Reglamento Roma III, que contempla de manera jerárquica que Ley resultará aplicable:

1. La ley en la que los cónyuges tengan su residencia habitual en el momento de la interposición de la demanda o, en su defecto,

2. La que los cónyuges hayan tenido su última residencia habitual, siempre que el período de residencia no haya finalizado más de un año antes de la interposición de la demanda, y que uno de ellos aún resida allí en el momento de la interposición de la demanda o, en su defecto;

3. La nacionalidad de ambos cónyuges en el momento de la interposición de la demanda o, en su defecto,

4. Aquella donde se ha interpuesta la demanda cuyos órganos jurisdiccionales se interponga la demanda.

Ahora la aplicación de la norma nos dirige al Reglamento 1103/2016 para los matrimonios y el 1104/2016 para las parejas de hecho registradas en lo que afecta a la competencia y ley aplicable en materia de efectos patrimoniales, así como para el reconocimiento y ejecución.

\subsection{Aplicación de la Ley según lo dispuesto en los Reglamentos 1103 y 1104 de la UE}

Debemos partir de dos cuestiones previas, una referida a la cooperación reforzada y otra con relación a las asimetrías existentes en esta materia en lo que a la regulación nacional tiene desarrollada cada Estado Miembro.

Respecto a la primera cuestión, debemos partir de lo dispuesto en el considerando 11 en cada uno de los respectivos reglamentos, donde Bélgica, Bulgaria, la República Checa, Grecia, Alemania, España, Francia, Croacia, Italia, Luxemburgo, Malta, los Países Bajos, Austria, Portugal, Eslovenia, Finlandia y Suecia expresando su deseo de esta- 
blecer una cooperación reforzada entre sí (durante los trabajo Chipre manifestó su deseo de participar en la cooperación reforzada) en el ámbito de los regímenes económicos de las parejas internacionales y, concretamente, de la competencia, la ley aplicable, el reconocimiento y la ejecución de resoluciones en materia de regímenes económicos matrimoniales, así como de la competencia, la ley aplicable, el reconocimiento y la ejecución de resoluciones en materia de efectos patrimoniales de las uniones registradas, y solicitaron a la Comisión que presentase una propuesta al Consejo a tal fin.

En cuanto a la segunda cuestión, debemos tener presente que seis países miembros de la UE no contemplan regulación alguna sobre las uniones registradas: Bulgaria, Letonia, Lituania, Polonia, Rumanía y Eslovaquia ni se regula el matrimonio entre personas del mismo sexo ni ningún otro tipo de unión civil.

Atendiendo a ambas cuestiones, se nos plantean tres escenarios posibles en lo que afecta a los matrimonios o parejas transnacionales para determinar la ley aplicable atendiendo a si hay o no cooperación reforzada: cuando ambos nacionales lo son de los países citados en el considerando 11 anteriormente enumerado, si solo uno de los nacionales de la pareja o consorte es nacional de un Estado que forma parte de la cooperación reforzada y el otro no, y cuando ninguno de los nacionales lo es de un Estado que se somete a la cooperación reforzada, en cuyo caso atenderemos a las normas de Derecho internacional privado, es decir, al Reglamento Roma III.

De tal manera que la aplicación o no del Reglamento (UE) 2016/1103 del Consejo, de 24 de junio, atenderá al derecho de libre elección de la Ley aplicable a través de un matrimonio celebrado entre personas de diferente sexo antes de la entrada en vigor de la norma y la diferencia en defecto de pacto de ley aplicable, junto con los efectos referidos a la aplicación temporal (retroactividad) y a las diferencias del derecho sustantivo existentes en Europa donde hay Estados como es España que tiene un sistema plurilegislativo.

A continuación, describiremos un caso práctico donde se analizarán elementos de conexión posibles a priori con múltiples Estados para establecer la competencia territorial y jurisdiccional con Estados que participan de la cooperación reforzada frente a otros que no lo hacen, a través del cual pretendemos analizar posibles variables.

\section{DESCRIPCIÓN DE UN CASO HIPOTÉTICO}

Un nacional sueco (país que participa de la cooperación reforzada y que regula el matrimonio y las uniones de hecho, del mismo sexo y distinto sexo) gerente de una multinacional, contrae matrimonio con una mujer irlandesa el 6 de enero de 2012 en Irlanda (país que no participa de la cooperación reforzada y que regula tanto el matrimonio como las parejas de hecho con el mismo o distinto sexo) cuya profesión es traductora a tiempo parcial.

Según ella, el lugar de residencia habitual de ambos tras la celebración del matrimonio fue Holanda, pero él dice que trabajaba en Suecia y vivía allí por lo que era imposible tener una residencia común tras la celebración del matrimonio, si bien reconoce que su esposa sí habitaba en los Países Bajos (Holanda), hasta que en julio de 2016 ambos se trasladan a vivir a Barcelona donde compran una casa y establecen su domicilio común. 
Tres años después, el 1 de diciembre de 2019, se separaron de hecho, trasladándose él a vivir a Alemania y permaneciendo ella en Barcelona (España).

Posteriormente, el 5 de febrero de 2020, él presenta la demanda de divorcio en los Juzgados de Barcelona, y solicita la disolución y liquidación del régimen económico matrimonial.

Se trata de un matrimonio compuesto por personas de diferentes nacionalidades de dos Estados miembros de la UE: Suecia e Irlanda, donde no queda claro en los hechos manifestados cuál es el lugar de residencia tras la celebración del matrimonio para determinar la ley aplicable y no consta que hubiera acuerdo o pacto. Pero si es evidente, que él trabaja en Suecia y ella en Holanda inmediatamente después de casarse, así como que en julio de 2016 se trasladan a vivir a Barcelona y que en febrero de 2020 él decide presentar demanda de divorcio, si bien unos meses antes se habían separado de hecho y él se traslada a Alemania.

Es importante recordar que, cuando el nacional sueco interpuso la demanda en 2020, el Reglamento (UE) 2016/1103 del Consejo, de 24 de junio, por el que se aplica una cooperación reforzada en materia de competencia, de ley aplicable y de reconocimiento y ejecución de resoluciones en materia de regímenes matrimoniales, ya estaba vigente. Si bien, el matrimonio se celebró antes de la entrada en vigor del citado Reglamento, concretamente en 2012. De manera, que no le sería aplicable porque este reglamento afectará a los matrimonios celebrados después de su entrada en vigor, es decir, a partir del 29 enero de 2019, si bien debemos recordar que se permitirá la elección de la ley posterior a esa fecha cuando el matrimonio se celebró previamente, pudiendo en tal caso entrar en aplicación el Reglamento (UE) 2016/1103.

Las cuestiones para analizar serán las referidas a la competencia del órgano jurisdiccional, así como la determinación de la ley aplicable cuando optan por la ley aplicable o en defecto de pacto, y la retroactividad de los efectos patrimoniales atendiendo a la voluntariedad de las partes. Para dar respuesta a estos contenidos planteamos las siguientes preguntas:

- ¿Cuál es el órgano jurisdiccional competente para la disolución de un matrimonio celebrado antes de la entrada en vigor del Reglamento 2016/1103?

- ¿Es necesario conocer el derecho sustantivo de cada uno de los Estados implicados en el caso como información previa al ejercicio del derecho de opción que tienen las partes a elegir la ley aplicable?

- Si las partes hubieran optado por aplicar el Reglamento 2016/1103, ¿hay variaciones en la determinación de la competencia del órgano jurisdiccional?

- De haber optado por la aplicación del Reglamento UE 2016/1103 ¿habría alguna diferencia?

- En defecto de acuerdo de las partes ¿Cómo se determinaría la ley aplicable?

- Desde cuando tendría la aplicación los efectos del régimen económico matrimonial bajo el Reglamento UE 2016/1103? ¿Cabe la retroactividad? 


\subsection{Variables que afectan a los divorcios tras la entrada en vigor del Reglamento UE 2016/1103}

\section{A ¿Cuál es el órgano jurisdiccional competente para la disolución de un matrimonio celebrado antes de la entrada en vigor del Reglamento 2016/1103?}

La competencia del órgano jurisdiccional de un matrimonio celebrado antes o después de la entrada en vigor del Reglamento (UE) 2016/1103 en defecto de elección de la ley aplicable (como es el caso en el que nos encontramos) se determinará bajo la aplicación del Reglamento de Bruselas II bis, para posteriormente valorar la ley aplicable al régimen económico tras la disolución por divorcio o muerte si por elección de los cónyuges fuera de aplicación el Reglamento (UE) 2016/1103.

El marco normativo que regula las crisis matrimoniales con elementos de extranjería se encuentra en dos reglamentos, que seguirán de aplicación desde el punto de vista territorial en los Estados que no participen de la cooperación reforzada y si en ellos bajo las normas de Derecho internacional privado o cuando las partes por opción determinen lo contrario:

- Uno referido a la competencia judicial internacional y al reconocimiento y ejecución de resoluciones se recogen en el Reglamento (CE) n. ${ }^{\circ}$ 2201/2003, del Consejo, de 27 de noviembre de 2003, relativo a la competencia, el reconocimiento y la ejecución de resoluciones judiciales en materia matrimonial y de responsabilidad parental (en adelante, Reglamento Bruselas II bis), que vincula a todos los Estados miembro de la Unión Europea con excepción de Dinamarca.

- Y el segundo, referido a la ley aplicable al divorcio y a la separación judicial, pero no a la nulidad matrimonial. El Reglamento (UE) n. ${ }^{\circ}$ 1259/2010 del Consejo, de 20 de diciembre de 2010, por el que se establece una cooperación reforzada en el ámbito de la ley aplicable al divorcio y a la separación judicial (en adelante, Reglamento Roma III), que vincula a 17 Estados miembro de la Unión Europea, entre los que se encuentra España.

En consecuencia, atenderemos al Reglamento Bruselas II bis cuyo artículo 3 recoge siete foros alternativos a los que debemos atender para resolver nuestro caso práctico.

Recordemos que el nacional sueco fue quien presentó la demanda de disolución del matrimonio ante los Juzgados de Barcelona y no en Alemania que era donde vivía en ese momento o en Suecia de donde era nacional y residió solo él tras la celebración del matrimonio. Por ello la competencia general en los asuntos relativos al divorcio, la separación judicial y la nulidad matrimonial, recaerá en los órganos jurisdiccionales del Estado miembro en cuyo territorio se encuentre:

- la residencia habitual de los cónyuges, o

- el último lugar de residencia habitual de los cónyuges, siempre que uno de ellos aún resida allí, o

- la residencia habitual del demandado, o

- en caso de demanda conjunta, la residencia habitual de uno de los cónyuges, o 
- la residencia habitual del demandante si ha residido allí durante al menos un año inmediatamente antes de la presentación de la demanda, o

- la residencia habitual del demandante en caso de que haya residido allí al menos los seis meses inmediatamente anteriores a la presentación de la demanda y que sea nacional del Estado miembro en cuestión o, en el caso del Reino Unido e Irlanda, tenga allí su domicilio.

Pues bien, atendiendo a lo expuesto el órgano competente para resolver el divorcio serían los tribunales españoles, pues la única residencia habitual común probada ante el órgano jurisprudencial sería en Barcelona, además ella reside aún allí y es la demandada.

Es un hecho constatable ante el órgano jurisdiccional competente que el demandante es un sujeto de nacionalidad sueca con residencia habitual en Alemania en el momento de presentación de la demanda, y que la demandada tiene nacionalidad irlandesa pero no reside allí, lo hace tras el matrimonio en Holanda y posteriormente lo hace en España, país en el que residían ambos cónyuges antes de separarse en 2019. Por lo tanto, bajo la aplicación del art. 3 del Reglamento Bruselas II bis, podemos afirmar que la demanda pueda presentarse en España y estos tribunales sean los competentes atendiendo a dos foros: por un lado, el foro de la última residencia habitual de los cónyuges siempre que uno de ellos aún resida allí y, por otro, la residencia habitual del demandado, pues el matrimonio se celebró antes de la entrada en vigor del Reglamento.

La disolución del vínculo matrimonial a través del divorcio implica consecuentemente la disolución y liquidación del régimen económico matrimonial, que hasta la entrada en vigor del Reglamento 2016/1103 estaba regulada en la normativa interna de Derecho internacional privado. De manera que la competencia judicial internacional de los tribunales españoles vendrá determinada por los foros recogidos en la LOPJ, como sería en nuestro caso el recogido en el artículo 22 bis LOPJ, referente al domicilio del demandado en España.

Mientras que la ley aplicable, se regulará atendiendo a los arts. 9.2 y 9.3 Código civil español para todo el territorio nacional: el párrafo segundo del artículo 9 para los cónyuges que han celebrado pactos o capitulaciones matrimoniales; y el párrafo tercero, para cuando no se hayan acordado.

Como no hubo elección de ley aplicable, y los cónyuges no tenían nacionalidad común en el momento de celebración del matrimonio, la ley aplicable a los efectos del divorcio y liquidación atenderá a lo dispuesto en el artículo 9.3 del Código civil español. Según el cual, resultará de aplicación la ley de la residencia habitual común inmediatamente posterior a la celebración del matrimonio, pero como no se acredita que existiera una residencia habitual común después de la celebración del matrimonio, se aplicará la ley del lugar de celebración del matrimonio, es decir, Irlanda.

De haber elegido los cónyuges la ley aplicable al tiempo de celebración del matrimonio, nos iríamos al 9.2 Código civil su opción hubiera estado entre la ley de la nacionalidad (Suecia o Irlanda) o de la residencia habitual de cualquiera de ellos (Suecia u Holanda). 


\section{B ¿Es necesario conocer el derecho sustantivo de cada uno de los Estados implicados en el caso como información previa al ejercicio del derecho de opción que tienen las partes a elegir la ley aplicable?}

La diferencia de una ley aplicable a otra es determinante en la liquidación legal del régimen económico en defecto de pacto, pues no es lo mismo el reparto en un régimen de comunidad de bienes que cuando la liquidación se corresponde con la separación de bienes.

Por eso entendemos que hay que considerar las diferentes posibilidades respecto del matrimonio del nacional sueco con una irlandesa algunas cuestiones que afectan al derecho sustantivo nacional de cada Estado miembro en lo que afecta a la liquidación del patrimonio matrimonial, pues ante una crisis matrimonial lo primero en los que la mayoría de las parejas piensan es en cómo va a quedar su economía tras la separación, el divorcio o la nulidad. Siendo en este sentido determinante conocer la ley aplicable por elección si la ha habido, o en su defecto, la que venga determinada legalmente de manera supletoria, es decir, siendo o no previsores, atiende a interés más beneficioso económicamente, y no a la nacionalidad o la residencia habitual por ser el marco normativo conocido por ellos; porque la práctica nos muestra que cualquier sociedad mercantil al igual que cuando se liquida la sociedad civil, las partes desean salir beneficiadas, con relación al resto de socios o comuneros, pero también, con relación a terceros acreedores si los hubiera.

Así, el nacional sueco que ingresaba más que su mujer, razonablemente preferirá la aplicación legal del régimen catalán de separación de bienes frente al holandés o el sueco donde rige la comunidad de bienes. Del mismo modo, la responsabilidad patrimonial de los cónyuges según el régimen legal aplicable va a variar en consecuencia. En este contexto y atendiendo al artículo 27 del Reglamento habrá que conocer: los bienes dentro del patrimonio, pues no es lo mismo una vivienda que sea el domicilio familiar de otra que no tenga esta protección. Es decir, será preciso clasificar las propiedades de bienes muebles e inmuebles atendiendo a las diferentes categorías y protección, porque en la regulación de la responsabilidad de cada uno de los cónyuges o de ambos frente a terceros no es lo mismo aplicar la ley de nacionalidad alemana estatutaria en la que los bienes aportados y adquiridos durante el matrimonio no se convierten en bienes comunes, mientras que las ganancias acumuladas adquiridas durante el matrimonio se igualan cuando finaliza el régimen patrimonial (art. 1363, párrafo 2 del BGB), diferente al régimen legal supletorio de gananciales regulado en el Código civil español.

Por otra parte, el régimen legal sueco donde rige la comunidad de bienes diferidos a través de la que cada uno de los cónyuges tienen derecho a la mitad del valor neto de los bienes conyugales tras la disolución, y donde además de ser titulares de un patrimonio común pueden ser titulares de un patrimonio privativo del que son libres individualmente de tomar decisiones sobre sus bienes, con excepción de la vivienda y enseres para el hogar, similar a lo regulado en el Código civil español y al holandés en cuanto al régimen legal de comunidad aplicable a los bienes, pero con una diferenciación fundamental: en el caso que estamos analizando, matrimonio celebrado antes del 1 de enero de 2018, todos los bienes que los cónyuges aportaran al matrimonio y los adquiridos durante el mismo pertenecerán a la comunidad patrimonial matrimonial al igual que las deudas. 
Esta situación ha cambiado recientemente para los cónyuges casados después del 1 de enero de 2018 tras la modificación que ha sufrido el Código civil Holandés. A partir de esta fecha los cónyuges pueden disponer de un patrimonio privativo derivado de donaciones o herencia a uno de ellos, y en consecuencia, también es posible que las deudas derivadas de los bienes excluidos de la comunidad sean privativas, así como de las deudas prematrimoniales; porque a partir de la fecha citada, ya no forman parte de la propiedad conjunta, salvo que de mutuo acuerdo los cónyuges dispongan lo contrario.

Por su parte, Irlanda y Cataluña, siguen un régimen y efectos diferentes a aplicar en el momento de la disolución del matrimonio y de liquidación del patrimonio.

En este sentido, recordemos que en Irlanda los cónyuges no pueden elegir régimen económico alguno para el matrimonio, lo que no sucede en la Comunidad Autónoma española de Cataluña, donde los cónyuges sí pueden elegir previamente al matrimonio, o posteriormente cambiarlo tantas veces como lo consideren oportuno, pues rige el principio de libre elección.

Ambos territorios tienen en común que en ellos rige el régimen legal de separaciones de bienes, y cierta similitud en lo que al uso de la vivienda familiar se refiere, porque en Irlanda cuando uno de los cónyuges tiene bajos ingresos, los tribunales procuran satisfacer las necesidades básicas asegurándole un hogar, similar a la atribución del uso de la vivienda familiar en favor del cónyuge más vulnerable que se produce en Cataluña.

Los efectos respecto de las cargas o deudas mantienen similitudes y diferencias, pues mientras es común a ambas normativas que cada cónyuge sea responsable de la administración, gestión y disposición de sus bienes, además de tomarse medidas adecuadas a evitar desequilibrios económicos, que permitan satisfacer tras la ruptura las necesidades básicas del cónyuge más vulnerable por carecer de ingresos o ser estos bajos en Irlanda, por su parte el Código de familia catalán regula la posibilidad de compensación económica por razón del trabajo9.

\subsection{Análisis de posibles escenarios}

\section{A Si las partes hubieran optado por aplicar el Reglamento 2016/1103, ¿hay variaciones en la determinación de la competencia del órgano jurisdiccional?}

La entrada en vigor del Reglamento implica que las partes que han celebrado su matrimonio anteriormente, puedan elegir libremente la ley aplicable de uno de los Estados de la Unión Europea bajo el Reglamento 2016/1103, en vigor desde el 29 de enero de 2019, y

9 La Compilación del Derecho Civil Catalán (Código Civil de Cataluña libro 3-Art. 232.5, prevé la posibilidad de compensación económica por razón del trabajo, de tal forma que, si un cónyuge ha trabajado para la casa sustancialmente más que el otro, tiene derecho a una compensación económica por esta dedicación siempre y cuando en el momento de la extinción del régimen por separación, divorcio, nulidad o muerte de uno de los cónyuges o, en su caso, del cese efectivo de la convivencia, el otro haya obtenido un incremento patrimonial superior. La regulación relativa a la forma de pago, acciones a las que se encuentra facultado el perjudicado frente a actos en perjuicio del derecho a la compensación, así como el ejercicio del mencionado derecho, se contempla en los Compilación del Derecho Civil Catalán art. 232.8, Compilación del Derecho Civil Catalán (art.232.9 , Compilación del Derecho Civil Catalán art.232.11. Añadir, que la Compilación del Derecho Civil Catalán art. 232.10 precisa a este respecto que el derecho a la compensación económica por razón de trabajo es compatible con los demás derechos de carácter económico que corresponden al cónyuge acreedor y deben tenerse en cuenta para fijar estos derechos y, si procede, para modificarlos. 
consecuentemente, con posible aplicación en 2020 año en el que se presenta la demanda de divorcio.

En el caso que estamos comentando, podemos suponer atendiendo bien, a las conexiones con la residencia habitual que se hacen desde el Reglamento Roma III, o bien, bajo la elección del Reglamento 2016/1103, no hay nada que objetar a la competencia judicial internacional asignada al tribunal de primera instancia de Cataluña. Si bien debemos recordar que bajo la aplicación del Reglamento $2016 / 1103^{10}$, la competencia jurisdiccional se entiende en sentido amplio ${ }^{11}$, porque incluye no solo a los órganos jurisdiccionales en el sentido estricto de la palabra, que ejercen funciones judiciales, sino también, por ejemplo, a los notarios de algunos Estados miembros como sucede en España desde la Ley de Jurisdicción Voluntaria de $2015^{12}$.

A partir de aquí, y atendiendo a lo dispuesto en el artículo 5 del Reglamento sobre el régimen matrimonial 2016/1103, el órgano jurisdiccional competente será el del Estado miembro ante el que se haya presentado una demanda de divorcio los que competentes para pronunciarse sobre las cuestiones relativas al régimen matrimonial que se planteen en relación con dicha demanda, acordes con las normas de competencia en materia de divorcio establecidas en el Reglamento Bruselas II bis (2201/2003), cuyo artículo 3 establece que un cónyuge puede presentar una demanda de divorcio, ante los tribunales del Estado miembro en el que tenga su residencia habitual si ha residido allí durante al menos un año inmediatamente antes de la presentación de la solicitud y el otro cónyuge aún resida allí, lo que se da en el caso planteado.

\section{B De haber optado por la aplicación del Reglamento UE 2016/1103 ¿habría alguna diferencia?}

El Reglamento de la UE 2016/1103 no adopta el criterio de la nacionalidad, sino que optan por el criterio de la residencia; y por tanto, no es necesario partir de la nacionalidad de los cónyuges para saber la ley aplicable atendiendo o no a la cooperación reforzada, ya que la residencia habitual se convierte en un elemento determinante a la hora de conocer la norma aplicable.

10 GUZMÁN ZAPATER, M. y PAZ-ARES RODRÍGUEZ, I: "La competencia judicial internacional en materia de disolución del régimen económico del matrimonio en el Reglamento UE núm. 2016/1103”. Crisis matrimoniales internacionales y sus efectos: derecho español y de la Unión Europea : estudio normativo y jurisprudencial / Mónica Guzmán Zapater (dir.), Mónica Herranz Ballesteros (dir.), 2018, ISBN 978-84-9190-394-9, págs. 277-316.

11 Considerando (29): El presente Reglamento debe respetar los distintos sistemas para resolver las cuestiones relativas al régimen económico matrimonial que se aplican en los Estados miembros. A efectos del presente Reglamento, el término «órgano jurisdiccional» debe entenderse en un sentido amplio, que incluye no solo a los órganos jurisdiccionales en el sentido estricto de la palabra, que ejercen funciones judiciales, sino también, por ejemplo, a los notarios de algunos Estados miembros que, en determinadas cuestiones del régimen económico matrimonial, ejercen funciones judiciales del mismo modo que los órganos jurisdiccionales, así como los notarios y los profesionales del Derecho que, en algunos Estados miembros, ejercen funciones judiciales en materia de régimen económico matrimonial por delegación de poderes de un órgano jurisdiccional. Todos los órganos jurisdiccionales, tal como se definen en el presente Reglamento, deben regirse por las normas de competencia establecidas en el mismo. Por el contrario, el término «órgano jurisdiccional» no debe incluir a las autoridades no judiciales de un Estado miembro facultadas con arreglo al Derecho nacional para resolver las cuestiones relativas al régimen económico matrimonial, como los notarios en la mayoría de los Estados miembros cuando, como suele ser el caso, no ejercen funciones judiciales.

12 Ley 15/2015, de 2 de julio, de la Jurisdicción Voluntaria. «BOE» núm. 158, de 3 de julio de 2015, páginas 54068 a 54201. https://www.boe.es/diario_boe/txt.php?id=BOE-A-2015-7391 
A partir de la residencia habitual, el reglamento desarrolla dos situaciones:

1. Ley aplicable por opción libremente elegida por las partes: Cuando los integrantes del matrimonio seleccionan la ley aplicable atendiendo al artículo 22 del Reglamento correspondiente, ejerciendo el derecho de opción por aplicar a su régimen matrimonial o de pareja registrada una de las leyes especificadas en el citado precepto. En este caso, los cónyuges o los miembros de la pareja podrán acordar la designación o la modificación de la ley aplicable a su régimen matrimonial, siempre que dicha ley sea una de las siguientes:

a. La ley del Estado en el que los cónyuges o uno de ellos, tenga su residencia habitual en el momento de la celebración del acuerdo;

b. La ley de un Estado de la nacionalidad de uno de los cónyuges o futuros cónyuges en el momento del acuerdo.

Esta opción no es ejercida por las partes en el caso que estamos analizando, pero imaginando que al residir conjuntamente hubieran realizado capitulaciones matrimoniales la ley catalana será la aplicable por ser la residencia que tenían en el momento de la celebración del acuerdo.

En nuestro caso teniendo presente que el Reglamento adopta el criterio de la residencia, y sólo uno de los consortes pertenece a un Estado que ha manifestado su voluntad respecto de la cooperación reforzada con relación a los citados Reglamentos y la otra parte es nacional de un Estado que no la adoptó, según el artículo 20, la ley concebida como aplicable por el Reglamento se aplica independientemente de que sea o no la ley de un Estado miembro. Por lo tanto, también podría ser aplicable a las consecuencias patrimoniales del matrimonio por aplicación universal del citado articulo en aquellos países que no se han manifestado en favor de la cooperación reforzada como es Irlanda, de conformidad con el Reglamento.

A partir de aquí, cuando hay elección seguiremos lo dispuesto en el artículo 22 en ambos Reglamentos y cuando falta la elección aplicaremos el artículo 26 del Reglamento (UE) 2016/1103. Ambas situaciones diferencian el orden jerárquico atendiendo a si han ejercido o no su derecho de opción a la ley aplicable y a la determinación de la jurisdicción internacional.

\section{En defecto de acuerdo de las partes ¿Cómo se determinaría la ley aplicable?}

Ante la falta de acuerdo sobre la elección de la ley aplicable con arreglo al artículo 22, deberemos aplicar lo dispuesto en el artículo 26 del correspondiente Reglamento, que establece una jerarquía que ayuda a determinar la ley aplicable al régimen matrimonial o de las parejas de hecho registradas. En virtud de esta disposición, la ley aplicable al régimen matrimonial/pareja registrada será la ley del Estado:

a. de la primera residencia habitual común de los cónyuges después de la celebración del matrimonio; o, en su defecto,

b. de la nacionalidad común de los cónyuges en el momento de la celebración del matrimonio; o, en su defecto, 
c. con los que los cónyuges tengan en común los vínculos más estrechos en el momento de la celebración del matrimonio.

Añadir que excepcionalmente y a instancia de cualquiera de los cónyuges con mas de una nacionalidad común (art.26.2) a quienes solo les serán de aplicación las letras a y c del apartado primero, la autoridad judicial competente para pronunciarse sobre las consecuencias patrimoniales de un matrimonio, según se determina en el párrafo tercero del artículo 26, podrá decidir la legislación de un Estado distinto de aquel cuya legislación sea aplicable en virtud del apartado 1, si la legislación de ese otro Estado atribuye consecuencias patrimoniales a la institución de la unión registrada y si el solicitante lo demuestra por esta vía de naturaleza excepcional que:

- los cónyuges tuvieron su última residencia habitual común en ese otro Estado durante un período de tiempo significativamente largo que en el Estado designado en virtud del apartado 1, letra a), y

- ambas partes se habían basado en la legislación de ese otro Estado para organizar o planificar sus relaciones patrimoniales.

Ambas conexiones reflejan cierta proximidad con las circunstancias personales de los cónyuges, estando además ordenados subsidiariamente, y fijados temporalmente, para evitar problemas de conflicto móvil. A modo de excepción y a instancia de cualquiera de los cónyuges, la autoridad judicial que tenga competencia para resolver sobre el régimen económico matrimonial podrá decidir que la ley de un Estado distinto del Estado cuya ley sea aplicable en virtud del apartado 1, letra a), regirá el régimen económico matrimonial si el demandante demuestra que: los cónyuges tuvieron su última residencia habitual común en ese otro Estado durante un período de tiempo considerablemente más largo que en el Estado de primera residencia habitual común de los cónyuges tras la celebración del matrimonio; y que ambos cónyuges se basaron en la ley de ese otro Estado para organizar o planificar sus relaciones patrimoniales.

En el considerando 49 del Reglamento 1103/2016 dice literalmente que en el caso de que no se elija la ley aplicable se atenderá a la escala ya analizada de puntos de conexión (primera residencia común habitual de los cónyuges inmediatamente después del matrimonio debe constituir el primer criterio, por encima de la ley de la nacionalidad común de los cónyuges en el momento de la celebración del matrimonio. Y en defecto de ambos criterios, pues no queda probado que no hay una primera residencia común habitual y los cónyuges no tienen una nacionalidad común en el momento de la celebración del matrimonio, el tercer criterio será la ley del Estado con el que los cónyuges tengan una conexión más estrecha. Al aplicar el último criterio todas las circunstancias deben ser tenidas en cuenta y debe quedar claro que estas conexiones deben ser las existentes en el momento de la celebración del matrimonio. Por eso, aplicar la ley irlandesa sería incongruente con el considerando 51 del Reglamento que legitima, en casos excepcionales, a la autoridad judicial de un Estado miembro, a instancia de cualquiera de los cónyuges, cuando los cónyuges se hayan trasladado al Estado de su residencia habitual por un largo período, poder llegar a la conclusión de que es la ley de ese Estado la que podrá aplicarse cuando los cónyuges la invoquen, teniendo como límite que su aplicación podrá perjudicar los derechos del tercero. 
Atendiendo a esta redacción parece que el tiempo más dilatado de residencia de ambos cónyuges constante matrimonio estuvo en España, y concretamente en la provincia de Barcelona, pero no basta con el cumplimiento de este único requisito, sino que es necesario que ambos organizaran sus relaciones patrimoniales durante los años de matrimonio bajo el código civil catalán y, en consecuencia, en separación de bienes.

Y según los hechos expuestos en la sentencia, entendemos que después de la celebración del matrimonio, no hubo residencia común si bien el período de residencia mas largo conjuntamente fue en Cataluña y por conexión, si atendemos a la ley del lugar de celebración del matrimonio, hay que aplicar el derecho irlandés, donde debemos recordar no existe el concepto de régimen económico matrimonial -solución propia del common law -, es decir, los bienes adquiridos antes y durante el matrimonio pertenecen a cada cónyuge, circunstancia que en la sentencia se ha asimilado a la existencia de una especie de régimen de separación de bienes.

Llegado a este punto, la única controversia entre los cónyuges sería si a la liquidación del patrimonio ganancial se les aplica el régimen de separación de bienes o el ganancial, sabiendo que en la región de Cataluña rige la separación de bienes, en Irlanda para el supuesto en que nos encontramos donde los cónyuges no han realizado pactos o capitulaciones matrimoniales no existe el concepto de régimen económico matrimonial, lo que ha sido entendido por la DGRN como una identidad con la separación de bienes históricamente. Por tanto, donde hallaremos la controversia es si resultara de aplicación el derecho holandés -donde el régimen económico matrimonial supletorio es el de comunidad de bienes, resultando que, salvo excepciones, los bienes que se adquieran posteriormente a la celebración del matrimonio forman parte de la comunidad ganancial.

Por tanto, es de aplicación el artículo 26 del Régimen Matrimonial del Reglamento 2016/1103, donde se regula la ley aplicable en defecto de elección de las partes, será de aplicación la correspondiente al Estado de la primera residencia habitual común de los cónyuges tras la celebración del matrimonio. La primera y única residencia habitual común fue en España, concretamente en la CCAA de Cataluña, tal como quedó demostrado objetivamente; por lo tanto, la ley española aplicable para la división de sus bienes, será el Código civil catalán, porque se cumplen dos condiciones: la residencia habitual de ella en Cataluña se mantiene tras la separación de hecho así como su intención de permanecer allí, ambos habían estado viviendo en este territorio durante los doce meses anteriores al cambio de residencia de él y presentación por su parte de la demanda de divorcio. Por lo tanto, los tribunales catalanes tienen jurisdicción para decidir sobre el divorcio y la división de sus bienes regirá la separación de bienes, pero diferenciando dos tiempos en lo que a la liquidación afecta: uno desde el inicio del matrimonio hasta su residencia en Cataluña rige el lugar de celebración del matrimonio (ley irlandesa) y desde que tuvieron su residencia en Cataluña el Código civil catalán.

\section{D ¿Desde cuando tendría la aplicación los efectos del régimen económico matrimonial bajo el Reglamento UE 2016/1103? ¿Cabe la retroactividad?}

La primera premisa se da, puesto que él (ciudadano sueco) es quien demanda y el período de tiempo mayor ha estado en Barcelona. Pero esta ley solo se aplicará desde la 
celebración del matrimonio, a menos que uno de los cónyuges no esté de acuerdo (en este supuesto la ley de ese otro Estado surtirá efecto a partir del establecimiento de la última residencia habitual común en dicho Estado, cuya aplicación no afectará negativamente a los derechos de terceros derivados de la ley aplicable en virtud del apartado 1, letra a); o cuando los cónyuges hayan celebrado capitulaciones matrimoniales con anterioridad al establecimiento de su última residencia habitual común en ese otro Estado.

Teniendo en cuenta que se casaron en 2012 y que la residencia habitual en Barcelona no se produce hasta 2016, puede suceder dos situaciones diferentes: una que es la menos probable, es que ella esté de acuerdo, en cuyo caso, la ley catalana surtirá efecto retroactivo desde la celebración del matrimonio. Y otra, que en nuestro caso es mas probable, sería que ella se opusiera, en tal caso, el Código civil catalán será de aplicación desde la fecha en 2016 que ambos fijaron su residencia habitual en Barcelona.

\section{CONCLUSIONES}

La principal conclusión es que se desplaza la importancia de la nacionalidad en favor de la residencia habitual, y consecuentemente de hace variar la ley aplicable en los Estados como España y Reino Unido que son plurinacionales, donde se permite la aplicación de sus normas.

Añadir, que el derecho de opción que se le otorga a las partes el Reglamento 2016/1103 implica que el impacto temporal de aplicación va mas allá de la fecha de entrada en vigor; y la retroactividad de los efectos desde la celebración del matrimonio dependerá de la voluntad de los cónyuges, pero si no se da, los efectos lo serán solo desde la celebración del acuerdo.

La división entre los países que participan de la cooperación reforzada y los que no, no supone un límite absoluto para la aplicación del Reglamento, pues bajo el principio de libre elección las partes pueden determinar su aplicación.

Finalmente, la disolución del vínculo matrimonial conlleva, junto con las más que evidentes consecuencias personales, una serie de implicaciones de índole patrimonial, entre las que se encuentra la disolución y liquidación del régimen económico matrimonial ${ }^{13}$. Dicha cuestión se encuentra regulada actualmente bajo el Reglamento (UE) 2016/1103 del Consejo, de 24 de junio de 2016, por el que se establece una cooperación reforzada en el ámbito de la competencia, la ley aplicable, el reconocimiento y la ejecución de resoluciones en materia de regímenes económicos matrimoniales (en adelante, Reglamento 2016/1103), quedando el Reglamento de Roma III ${ }^{14}$ de aplicación conforme a las normas de conflicto de Derecho internacional privado cuando las partes no elijan la ley aplicable en alguno de los 18 países que participan de la cooperación reforzada o esta no resulte aplicable.

13 BOELE-WOELKI, K. FERRAND, F., GONZÁlEZ BEILFUSS, C., JÄNTERÄ-JAREBORG, M., LOWE, N., MARTINY, D. y PINTENS, W. (eds.): Principles of European family law regarding property relations between spouses , Intersentia, Cambridge-Antwerp-Portland, 2013 y BOELE-WOELKI, K., BRAAT, B. y CURRYSUMMER, I. (eds.): European family law in action: Property relations between spouses, vol. IV, Intersentia, Antwerp-Oxford-Portland, 2008.

14 Un análisis general del Reglamento, así como respecto de algunas cuestiones concretas del mismo puede encontrarse en ESPLUGUES MOTA, C. Y GUZMÁN ZAPATER, M. (dirs.) y HERRANZ BALLESTEROS, M. y VARGAS GÓMEZ-URRUTIA, M. (coords.): El derecho internacional privado de familia, Tirant lo Blanch, Valencia, 2017, 


\section{BIBLIOGRAFÍA}

Adam Muñoz, M.d., Añoveros Terradas, B. Mota, H, Perez Martín, L.A. Y Quinzá Redondo, P. «La unificación -fragmentada- del derecho internacional privado de la unión europea en materia de régimen económico matrimonial: El reglamento 2016/1103», Revista general de derecho europeo, núm. 41, 2017, pp. 180-222.

Alvarez Lata, N. “Las parejas de hecho: perspectiva jurisprudencial”. Dialnet. 1998.

AÑoveros TerradAs, B. «El régimen conflictual de las capitulaciones en los nuevos reglamentos de la Unión Europea en materia de regímenes económicos matrimoniales y efectos patrimoniales de las uniones registradas», Anuario español de derecho internacional privado, núm. 17, 2017.

Boele-Woelki, K., Ferrand, F., González Beilfuss, C., Jänterä-Jareborg, M., Lowe, N., Martiny, D. Y Pintens, W. (EDS.). Principles of European family law regarding property relations between spouses , Intersentia, Cambridge-Antwerp-Portland, 2013.

Boele-Woelki, K., BraAt, B. Y Curry-Summer, I. (Eds.). European family law in action: Property relations between spouses, vol. IV, Intersentia, Antwerp-Oxford-Portland, 2008.

Esplugues Mota, C. Y Guzmán Zapater, M. (Dirs.) Y Herranz Ballesteros, M. Y Vargas GóMEZ-UrRutia, M. (Coords.). El derecho internacional privado de familia, Tirant lo Blanch, Valencia, 2017.

FERNÁNDEz Rozas, J.C. «Un hito más en la comunitarización del Derecho internacional privado: regímenes económico matrimoniales y efectos patrimoniales de las uniones registradas», La Ley Unión Europea, núm. 40, 30 septiembre 2016.

GuZmán Zapater, M. Y PAZ-Ares Rodríguez, I. "La competencia judicial internacional en materia de disolución del régimen económico del matrimonio en el Reglamento UE núm. 2016/1103”. Crisis matrimoniales internacionales y sus efectos: derecho español y de la Unión Europea : estudio normativo y jurisprudencial / Mónica Guzmán Zapater (dir.), Mónica Herranz Ballesteros (dir.), 2018, ISBN 978-84-9190-394-9.

JimÉnEZ Blanco, P. "La movilidad transfronteriza de matrimonios entre personas del mismo sexo: la UE da un paso. Sentencia del Tribunal de Justicia de 5 de junio de 2018, asunto C-673/18: Coman". La Ley Unión Europea, N. ${ }^{\circ}$ 61, 31 de Julio de 2018.

Peiteado Mariscal, P. «Competencia internacional por conexión en materia de régimen económico matrimonial y de efectos patrimoniales de uniones registradas. Relación entre los Reglamentos UE 2201/2003, 650/2012, 1103/2016 y 1104/2016», Cuadernos de derecho transnacional, vol. 9, núm. 1, 2017, pp. 300-326.

Rodríguez BenOt, A. En «La armonización del régimen económico matrimonial en la Unión Europea: la propuesta de Reglamento marzo 2011», Nuevas fronteras del Derecho de la Unión Europea. Liber amicorum José Luis Iglesias Buhigues, Valencia, Tirant lo Blanch, Valencia, 2012, pp. 555-572.

donde se encuentran varios trabajos en la materia (particularmente tratando cuestiones específicas del Reglamento 2016/1103, los trabajos de ADAM MUÑOZ, M.D; AÑOVEROS TERRADAS, B.; MOTA, H, PEREZ MARTÍN, L.A. y QUINZÁ REDONDO, P.); QUINZÁ REDONDO, P.: «La unificación -fragmentada- del derecho internacional privado de la unión europea en materia de régimen económico matrimonial: El reglamento 2016/1103», Revista general de derecho europeo, núm. 41, 2017, pp. 180-222; FERNÁNDEZ ROZAS, J.C.: «Un hito más en la comunitarización del Derecho internacional privado: regímenes económico matrimoniales y efectos patrimoniales de las uniones registradas», La Ley Unión Europea , núm. 40, 30 septiembre 2016 pp. 1-21; PEITEADO MARISCAL, P.: «Competencia internacional por conexión en materia de régimen económico matrimonial y de efectos patrimoniales de uniones registradas. Relación entre los Reglamentos UE 2201/2003, 650/2012, 1103/2016 у 1104/2016», Cuadernos de derecho transnacional , vol. 9, núm. 1, 2017, pp. 300-326; AÑOVEROS TERRADAS, B.: «El régimen conflictual de las capitulaciones en los nuevos reglamentos de la Unión Europea en materia de regímenes económicos matrimoniales y efectos patrimoniales de las uniones registradas», Anuario español de derecho internacional privado, núm. 17, 2017, pp. 821-845. Igualmente, aunque respecto de la Propuesta de Reglamento, se recomienda la lectura de RODRÍGUEZ BENOT, A., en «La armonización del régimen económico matrimonial en la Unión Europea: la propuesta de Reglamento marzo 2011», Nuevas fronteras del Derecho de la Unión Europea. Liber amicorum José Luis Iglesias Buhigues, Valencia, Tirant lo Blanch, Valencia, 2012, pp. 555-572. 